\title{
The Association of Preoperative Body Mass Index with Acute Kidney Injury in Liver Transplantation Recipients: A Retrospective Study
}

\author{
Ju Yeon Park, Jung-Hyun Park, Su Sung Lee, Hyun-Su Ri, Hye-jin Kim, \\ Yun Mi Choi, Yoon Ji Choi, and Ji-Uk Yoon
}

Department of Anesthesia and Pain Medicine, Pusan National University Yangsan Hospital, Yangsan, Korea

\begin{abstract}
Background: Liver transplantation (LT) is a complicated procedure with a high incidence of postoperative acute kidney injury (AKI). Previous studies indicate that even transient or mild post-LT AKI can result in critical conditions, including prolonged stays in hospitals and intensive care units and increased morbidity and mortality. The aim of this study was to investigate the association between body mass index (BMI) and occurrence of AKI in LT recipients.

Methods: Medical data from 203 patients who received LT surgery from January 2010 to August 2016 in a single university hospital setting were retrospectively collected and analyzed. Patients were classified as either underweight $\left(\mathrm{BMl}<20 \mathrm{~kg} / \mathrm{m}^{2}\right)$ or normal weight $\left(20 \leq \mathrm{BMI}<30 \mathrm{~kg} / \mathrm{m}^{2}\right)$. Demographic data, anesthetic methods, complications, and perioperative laboratory test values of each patient were assessed. Propensity analyses and logistic regression were performed to evaluate the association between BMI and post-LT AKI.

Results: There was no significant difference in occurrence of post-LT AKI between underweight and normal weight patients. The underweight patient group had significantly longer hospital stay compared with the normal weight patient group $(P=0.023)$.

Conclusions: BMI classification was neither a positive nor negative predictor of postoperative AKI occurrence. However, patients with lower BMI had significantly longer hospital stay compared with their counterparts. Although our study was limited by its retrospective design, our observations suggest that lower BMI might play a role in post-LT AKI.
\end{abstract}

Key Words: acute kidney injury; body mass index; liver transplantation.

\section{Introduction}

Liver transplantation (LT) is currently the standard treatment for patients with end-stage liver disease. It is a complex high-risk surgery with a high incidence of postoperative acute kidney injury (AKI), which is reported in $5 \%$ to $50 \%$ of LT recipients [1]. Post-LT AKI etiology is thought to be multifactorial. In addition to the general risks associated with any major operation, exposure to high levels of toxic free-radicals, renal ischemia, use of medications with nephrotoxic properties, sepsis, surgery-related events including blood loss and hypotension, calcineurin inhibitor-induced vasoconstriction, and the effects of end-stage liver disease on the kidney are all additional risks of LT [2,3]. Furthermore, preexisting hepatorenal syndrome, intravascular volume depletion, and infection can predispose patients to renal dysfunction prior to LT [4-6]. Therefore, changes in serum creatinine (sCr) are very common posttransplantation [1,7].

Received on March 22, 2017 Revised on June 20, 2017 Accepted on June 26, 2017

Correspondence to: Yoon Ji Choi, Department of Anesthesia and Pain Medicine, Pusan National University Yangsan Hospital, 20 Geumo-ro, Mulgeum-eup, Yangsan 50612, Korea Tel: +82-55-360-2129, Fax: +82-55-360-2149, E-mail: yoonji07@gmail.com

*No potential conflict of interest relevant to this article was reported.

(cc) This is an Open Access article distributed under the terms of the Creative Commons Attribution Non-Commercial License (http:/creativecommons.org/ licenses/by-nc/4.0/) which permits unrestricted non-commercial use, distribution, and reproduction in any medium, provided the original work is properly cited. Copyright (c) 2017 The Korean Society of Critical Care Medicine 
In contrast to the conventional view of AKI progression-that complete recovery to former kidney function is anticipated in a majority of patients - recent studies have shown that patients who experience an AKI event have a significant risk for advancement to chronic kidney disease and even end-stage renal disease [8,9]. In a systematic review and meta-analysis, Coca et al. [10] reported that an AKI event increased the risk for developing chronic kidney disease by 8.8 times compared with controls and patients with end-stage renal disease, whose risk was increased 3.1 times [11]. Previous literature indicates that even transient or mild post-LT AKI can result in critical conditions, including prolonged intensive care unit (ICU) or hospital stays and increased morbidity and mortality, reported in up to $50 \%$ of patients. Additionally, AKI occurring within the first 72 hours after LT has been reported to be associated with decreased graft survival $[1,12]$.

Based on a recent study demonstrating that lower body mass index (BMI) is an independent risk factor for renal function deterioration [13], we hypothesized that lower
BMI negatively affects postoperative renal function. The aim of this retrospective study was to investigate the association of BMI with AKI occurrence in LT recipients.

\section{Materials and Methods}

This retrospective study was approved by institutional review board (No. 05-2016-111) of Pusan National University Yangsan Hospital. The medical records of 334 patients who had received LT from January 2010 to August 2016 at Pusan National University Yangsan Hospital were reviewed from our transplantation database.

A flow diagram of patients throughout the study is presented in Figure 1. Patients were excluded if they had undergone repeat surgery or if there was any missing data on weight, height, or short- and long-term outcomes. Patients with pretransplant renal failure requiring renal replacement therapy (RRT) were excluded because AKI development was not in question in these patients. The final cohort consisted of 203 patients. Patients were classified as under-

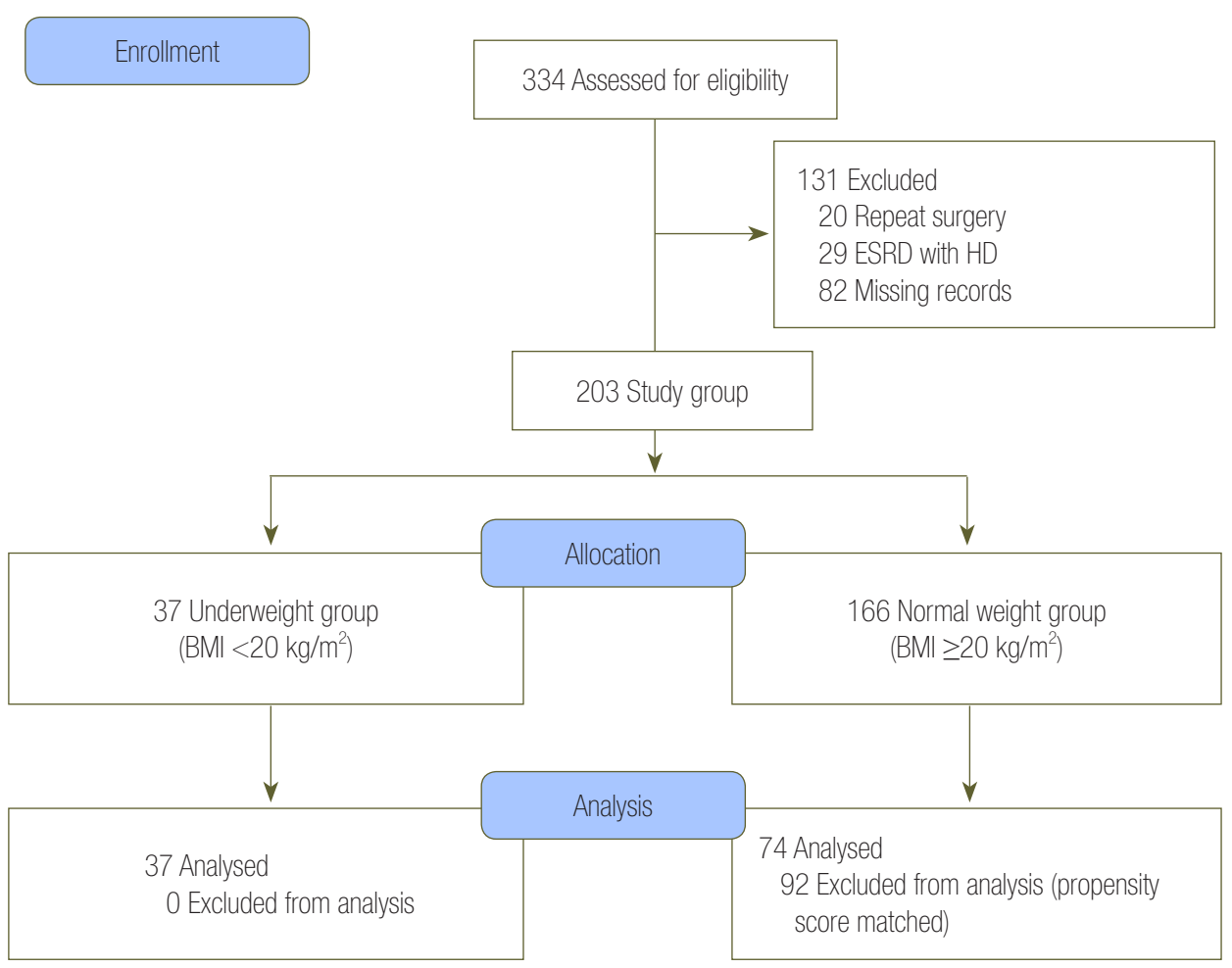

Figure 1. A flow diagram of the progress through the study. ESRD: end-stage renal disease; HD: hemodialysis; BMI: body mass index. 
weight (BMI $\left.<20 \mathrm{~kg} / \mathrm{m}^{2}\right)$, normal weight $(20 \leq \mathrm{BMI}<30$ $\mathrm{kg} / \mathrm{m}^{2}$ ), or obese (BMI $\geq 30 \mathrm{~kg} / \mathrm{m}^{2}$ ) based on previous studies $[14,15]$. BMI was calculated by dividing patient weight in kilograms by the square of height in meters $\left(\mathrm{kg} / \mathrm{m}^{2}\right)$.

General anesthesia was induced using propofol, remifentanil, and rocuronium or cisatracurium and was maintained using inhaled anesthetic gas (sevoflurane or desflurane), a $40 \%$ to $50 \%$ oxygen/air mixture, and continuous infusion with remifentanil and muscle relaxant. Packed red blood cells were transfused during surgery to maintain a hematocrit concentration of $25 \%$ to $30 \%$. Although epinephrine use was managed by a well-trained anesthesiologist who was responsible for each case, the first-line vasopressor during surgery was norepinephrine. If norepinephrine was ineffective, dobutamine, vasopressin, and epinephrine were considered. A calcineurin inhibitor (cyclosporine or tacrolimus) and corticosteroids were used as the primary immunosuppressive regimen. Postoperatively, patients received infusions of prostaglandin E1 $(0.01 \mu \mathrm{g} / \mathrm{kg} / \mathrm{min})$, methylprednisolone (125 $\mathrm{mg} / \mathrm{d}$ ), cyclophosphamide (2 mg/kg/d), and mycophenolate mofetil (starting dose of $500 \mathrm{mg} / \mathrm{d}$, followed by maintenance dose of $1,000 \mathrm{mg} / \mathrm{d}$ ). Standard monitoring was applied to all patients, including electrocardiogram, end-tidal $\mathrm{CO}_{2}$ concentration, bispectral index, peripheral $\mathrm{O}_{2}$ saturation, cerebral blood oxygenation, and invasive arterial monitoring from the radial and femoral arteries. Subsequently, an oximetry central venous catheter (PreSep; Edwards Lifesciences, Irvine, CA, USA) was inserted and connected to an EV1000 monitoring platform (Edwards Lifesciences) to monitor cardiac output, cardiac index, stroke volume, stroke volume index, central venous oxygen saturation, and systemic vascular resistance index; these parameters were used to evaluate fluid and circulatory management.

Data were collected at three time points: preoperative, intraoperative, and postoperative. The following preoperative data were included: patient demographics, etiology of end-stage liver disease, Model for End-Stage Liver Disease (MELD) score, Child-Pugh score, medications that potentially affect kidney function, preoperative comorbidities, and laboratory data. Intraoperative data included anesthesia duration, estimated blood loss, epinephrine use, and development of postreperfusion syndrome. Total volume of fluid intake, volume and type of blood products used, and urine output were also included in the analyses. Postoperative data included ICU and total hospital stay, application of RRT, survival at 6-month post-LT, and daily $\mathrm{sCr}$ for the first 48 hours after LT, which was used to diagnose AKI.

The presence or absence of AKI in the postoperative period was determined according to the Acute Kidney Injury Network (AKIN) criteria, which classify severity using the following system: stage 1: $\mathrm{sCr}$ increase 1.5 times greater than baseline, $\mathrm{sCr} \geq 0.3 \mathrm{mg} / \mathrm{dl}$, or decreased urine output $<0.5 \mathrm{ml} / \mathrm{kg} / \mathrm{h}$ for at least 6 hours; stage 2: $>2$-fold increase in $\mathrm{sCr}$ from baseline or urine output $<0.5 \mathrm{ml} / \mathrm{kg} / \mathrm{h}$ for at least 12 hours; stage 3: more than 3-fold increase in $\mathrm{sCr}$ from baseline or $\mathrm{sCr} \geq 4 \mathrm{mg} / \mathrm{dl}$, acutely increased by more than $0.5 \mathrm{mg} / \mathrm{dl}$, decreased urine output $<0.3 \mathrm{ml} / \mathrm{kg} / \mathrm{h}$ for at least 24 hours, or anuria for more than 12 hours. Patients were considered to have stage-3 AKI if RRT was introduced [16]. AKI was diagnosed within 48 hours postoperatively in this study.

To minimize selection bias before comparing the underweight and normal weight groups, propensity score matching was utilized. Propensity score was calculated as the odds of a subject receiving treatment based on the subject's covariate profile. To generate propensity scorematched pairs without replacement, each underweight patient was matched with two normal weight patients undergoing LT. Patient characteristics, including age, sex, cause of LT, MELD score, Child-Pugh score, presence of preoperative ascites, hepatic encephalopathy, esophageal varix, hepatorenal syndrome, preoperative medications, and underlying systemic diseases, were all variables included in propensity score matching. Continuous variables were expressed as mean \pm standard deviation, and categorical variables were expressed as number and percentage. Between-group differences in continuous variables were compared with Student t-test or Mann-Whitney test, and differences in categorical variables were 
compared with the chi-square test or Fisher exact test, as appropriate. Data analysis was performed using IBM SPSS version 21.0 (IBM Corp., Armonk, NY, USA), and a P-value $<0.05$ was considered statistically significant.

\section{Results}

The final dataset included 203 patients, 37 in the underweight group (BMI $<20 \mathrm{~kg} / \mathrm{m}^{2}$ ) and 166 in the normal weight group $\left(20 \leq \mathrm{BMI}<30 \mathrm{~kg} / \mathrm{m}^{2}\right)$. There were only five patients classified as obese (BMI $\geq 30 \mathrm{~kg} / \mathrm{m}^{2}$ ). Unfortunately, all five patients in the obese group were initially

Table 1. Patient characteristics

\begin{tabular}{|c|c|c|c|c|}
\hline Characteristic & $\begin{array}{c}\mathrm{BMI}<20 \mathrm{~kg} / \mathrm{m}^{2} \\
(\mathrm{n}=37)\end{array}$ & $\begin{array}{c}\mathrm{BMI} \geq 20 \mathrm{~kg} / \mathrm{m}^{2} \\
\quad(\mathrm{n}=166)\end{array}$ & $\begin{array}{c}\mathrm{BMI} \geq 20 \mathrm{~kg} / \mathrm{m}^{2} \\
\quad(\mathrm{n}=74)^{\mathrm{a}}\end{array}$ & P-value ${ }^{a}$ \\
\hline Age (yr) & $53.68 \pm 8.91$ & $53.39 \pm 7.87$ & $54.38 \pm 7.33$ & 0.66 \\
\hline Sex (female : male) & $11(29.7): 26(70.3)$ & $48(28.9): 118$ (71.1) & $16(21.6): 58(78.4)$ & 0.35 \\
\hline Cause of LT & & & & 0.72 \\
\hline HBV & $4(48.6)$ & $99(59.6)$ & $39(52.7)$ & \\
\hline HBV \& HCV & 0 & $6(3.6)$ & 0 & \\
\hline $\mathrm{HCV}$ & $4(10.8)$ & 18 (10.8) & $8(10.8)$ & \\
\hline Autoimmune hepatitis & $5(13.5)$ & $13(7.8)$ & $5(6.8)$ & \\
\hline Alcholics & $8(21.6)$ & 27 (16.3) & $20(27.0)$ & \\
\hline Primary biliary cirrhosis & $2(5.4)$ & $3(1.8)$ & $2(2.7)$ & \\
\hline DDLT : LDLT & $18(48.6): 19(51.4)$ & $45(27.1): 121$ (72.9) & $24(32.4): 50(67.6)$ & 0.10 \\
\hline MELD score & $17.49 \pm 9.17$ & $15.65 \pm 9.43$ & $16.77 \pm 8.11$ & 0.68 \\
\hline Child-Pugh score & & & & 0.79 \\
\hline A & $7(18.9)$ & $78(47.0)$ & $18(24.3)$ & \\
\hline B & $12(32.4)$ & $35(21.1)$ & $24(32.4)$ & \\
\hline C & $18(48.6)$ & $53(31.9)$ & $32(43.2)$ & \\
\hline Ascites & $12(32.4)$ & $40(24.1)$ & $24(32.4)$ & 1 \\
\hline Hepatic encephalopathy & $4(10.8)$ & $20(12.0)$ & $9(12.2)$ & 1 \\
\hline Esophageal varix & $7(18.9)$ & $22(13.3)$ & $16(21.6)$ & 0.74 \\
\hline HRS & $4(10.8)$ & $8(4.8)$ & $4(5.4)$ & 0.44 \\
\hline \multicolumn{5}{|l|}{ Preop medication } \\
\hline Diuretics & $9(24.3)$ & $27(16.3)$ & 18 (24.3) & 1 \\
\hline Insulin & $1(2.7)$ & $5(3.0)$ & $3(4.1)$ & 1 \\
\hline NSAID & 0 & 0 & 0 & 0 \\
\hline ARB & 0 & 0 & 0 & 0 \\
\hline ACEi & 0 & 0 & 0 & 0 \\
\hline B-blocker & 0 & $1(0.6)$ & 0 & 0 \\
\hline Hypertension & $9(24.3)$ & $29(17.5)$ & $14(18.9)$ & 0.51 \\
\hline Diabetes mellitus & $11(29.7)$ & $37(29.7)$ & $21(28.4)$ & 0.88 \\
\hline
\end{tabular}

Values are presented as mean \pm standard deviation or number (\%).

BMI: body mass index; LT: liver transplantation; HBV: hepatitis B virus; HCV: hepatitis C virus; DDLT: deceased-donor liver transplantation; LDLT: living-donor liver transplantation; MELD: Model for End-Stage Liver Disease; HRS: hepatorenal syndrome; Preop: preoperative; NSAID: nonsteroidal anti-inflammatory drug; ARB: angiotensin receptor blocker; ACEi: angiotensin converting enzyme inhibitor.

aPropensity score matched values. 
excluded due to incomplete medical records.

All patient demographic and medical data used in the analysis are listed in Table 1. There was a significant difference in the number of patients who received either deceased-donor LT or living-donor LT between the two groups $(\mathrm{P}=0.01)$. After propensity adjustment, the two groups did not differ in any of the patient characteristics.

Preoperative laboratory data are shown in Table 2. There was significant difference in preoperative hemoglobin level between the two patient groups $(\mathrm{P}=0.01)$, without any differences in preoperative liver function, electrolytes, sCr, or glucose tests. After propensity adjustment, the two groups did not differ in any of the preoperative laboratory data listed in Table 2.

Patient perioperative factors, including anesthesia duration, estimated blood loss, total volume of fluid intake, transfusion volume per blood product, postreperfusion syndrome occurrence, epinephrine use, and urine output, are listed in Table 3. There were no differences in anesthesia duration or fluid balance between the two groups before or after propensity adjustments.

AKI occurred in $35.1 \%$ of patients $(n=13)$ in the un-

Table 2. Preoperative laboratory data

\begin{tabular}{|c|c|c|c|c|}
\hline Variable & $\begin{array}{c}\mathrm{BMI}<20 \mathrm{~kg} / \mathrm{m}^{2} \\
(\mathrm{n}=37)\end{array}$ & $\begin{array}{c}\mathrm{BMI} \geq 20 \mathrm{~kg} / \mathrm{m}^{2} \\
(\mathrm{n}=166)\end{array}$ & $\begin{array}{c}\mathrm{BMI} \geq 20 \mathrm{~kg} / \mathrm{m}^{2} \\
\quad(\mathrm{n}=74)^{\mathrm{a}}\end{array}$ & P-value ${ }^{a}$ \\
\hline $\mathrm{Hb}(\mathrm{g} / \mathrm{dl})$ & $10.26 \pm 2.13$ & $11.23 \pm 2.15$ & $10.57 \pm 2.00$ & 0.45 \\
\hline AST (IU/L) & $59.59 \pm 43.44$ & $65.15 \pm 70.95$ & $57.41 \pm 36.53$ & 0.78 \\
\hline ALT (IU/L) & $33.16 \pm 25.01$ & $54.41 \pm 43.44$ & $32.53 \pm 21.89$ & 0.89 \\
\hline Bilirubin (mg/dl) & $7.37 \pm 9.48$ & $7.00 \pm 11.52$ & $6.75 \pm 9.60$ & 0.75 \\
\hline Protein (g/dl) & $5.65 \pm 1.29$ & $6.61 \pm 1.77$ & $5.82 \pm 0.75$ & 0.46 \\
\hline Albumin (g/dl) & $3.86 \pm 0.66$ & $3.15 \pm 0.51$ & $3.08 \pm 0.50$ & 0.31 \\
\hline $\mathrm{Na}(\mathrm{mEq} / \mathrm{L})$ & $136.73 \pm 4.70$ & $136.41 \pm 15.70$ & $136.84 \pm 5.26$ & 0.92 \\
\hline $\mathrm{K}(\mathrm{mEq} / \mathrm{L})$ & $3.90 \pm 0.41$ & $4.66 \pm 1.76$ & $3.98 \pm 0.54$ & 0.45 \\
\hline Creatinine (mg/dl) & $0.77 \pm 0.28$ & $0.91 \pm 0.71$ & $0.84 \pm 0.46$ & 0.40 \\
\hline Glucose (mg/dl) & $125.57 \pm 32.72$ & $132.39 \pm 83.48$ & $124.84 \pm 30.36$ & 0.91 \\
\hline
\end{tabular}

Values are presented as mean \pm standard deviation.

BMl: body mass index; Hb: hemoglobin; AST: aspartate transaminase; ALT: alanine transaminase; Na: sodium; K: potassium.

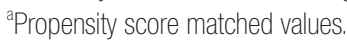

Table 3. Patients' perioperative factors

\begin{tabular}{|c|c|c|c|c|}
\hline Variable & $\mathrm{BMI}<20 \mathrm{~kg} / \mathrm{m}^{2}(\mathrm{n}=37)$ & $\mathrm{BMI} \geq 20 \mathrm{~kg} / \mathrm{m}^{2}(\mathrm{n}=166)$ & $\mathrm{BMI} \geq 20 \mathrm{~kg} / \mathrm{m}^{2}(\mathrm{n}=74)^{\mathrm{a}}$ & P-value ${ }^{a}$ \\
\hline Anesthetic time (h) & $10.69 \pm 3.19$ & $11.68 \pm 2.9$ & $11.01 \pm 2.13$ & 0.53 \\
\hline $\mathrm{EBL}(\mathrm{ml})$ & $3,348.14 \pm 2,252.94$ & $3,797.89 \pm 4,084.78$ & $3,348.14 \pm 3,276.32$ & 0.39 \\
\hline Total fluid intake (units) & $8,268.19 \pm 6,198.81$ & $9,297.12 \pm 5,465.31$ & $3,811.49 \pm 3,276.32$ & 0.62 \\
\hline $\mathrm{pRBC}$ & $6(0-25)$ & $7(0-93)$ & $8(0-37)$ & \\
\hline FFP & $6.5(2-21)$ & $8(1-75)$ & $10(2-35)$ & \\
\hline Cryo & $10(5-13)$ & $8(5-32)$ & $6(5-16)$ & \\
\hline PLT & $12(0-20)$ & $8(0-40)$ & $8(0-32)$ & \\
\hline Postreperfusion syndrome & $32(86.5)$ & $155(93.4)$ & $69(93.2)$ & 0.33 \\
\hline Epinephrine during reperfusion & $31(83.8)$ & $147(88.6)$ & $68(91.9)$ & 0.37 \\
\hline Urine (ml) & $817.49 \pm 630.56$ & $995.81 \pm 812.73$ & $862.32 \pm 765.56$ & 0.60 \\
\hline
\end{tabular}

Values are presented as mean \pm standard deviation, mean (range), or number (\%).

BMI: body mass index; EBL: estimated blood loss; pRBC: packed red blood cells; FFP: fresh frozen plasma; Cryo: cryoprecipitate; PLT: platelet.

aPropensity score matched values. 
Table 4. Effect of BMI on postoperative AKI in LT recipients

\begin{tabular}{|c|c|c|c|}
\hline Variable & $\mathrm{BMI}<20 \mathrm{~kg} / \mathrm{m}^{2}(\mathrm{n}=37)$ & $\mathrm{BMI} \geq 20 \mathrm{~kg} / \mathrm{m}^{2}(\mathrm{n}=74)^{\mathrm{a}}$ & P-value ${ }^{a}$ \\
\hline \multicolumn{4}{|l|}{ All patients } \\
\hline AKI incidence & $13(35.1)$ & $30(40.5)$ & 0.58 \\
\hline AKIN stage & & & 0.43 \\
\hline 0 (no AKI) & $24(64.9)$ & 44 (59.5) & \\
\hline 1 & $10(27.0)$ & $23(31.1)$ & \\
\hline 2 & $2(5.4)$ & $7(9.5)$ & \\
\hline 3 & $1(2.7)$ & 0 & \\
\hline \multicolumn{4}{|c|}{ Within normal range of $\mathrm{s} C r$} \\
\hline AKI incidence & $13(35.1)$ & $27(36.5)$ & 0.27 \\
\hline AKIN stage & & & 0.36 \\
\hline 0 (no AKI) & $23(62.2)$ & $38(51.4)$ & \\
\hline 1 & $10(27.0)$ & $20(27.0)$ & \\
\hline 2 & $2(5.4)$ & $7(9.5)$ & \\
\hline 3 & $1(2.7)$ & 0 & \\
\hline
\end{tabular}

Values are presented as number (\%).

BMl: body mass index; AKI: acute kidney injury; LT: liver transplantation; AKIN: Acute Kidney Injury Network; sCr: serum creatinine.

aPropensity score matched values.

Table 5. Postoperative outcomes

\begin{tabular}{|c|c|c|c|}
\hline Variable & $\mathrm{BMI}<20 \mathrm{~kg} / \mathrm{m}^{2}(\mathrm{n}=37)$ & $\mathrm{BMI} \geq 20 \mathrm{~kg} / \mathrm{m}^{2}(\mathrm{n}=74)^{\mathrm{a}}$ & P-value \\
\hline ICU stay (d) & $12.41 \pm 10.96$ & $10.0 \pm 8.8$ & 0.21 \\
\hline Hospital stay (d) & 35 (14-222) & $26(15-110)$ & $0.02^{c}$ \\
\hline RRT & $1(2.7)$ & $3(4.1)$ & 1 \\
\hline Death & $2(5.4)$ & $2(2.7)$ & 0.60 \\
\hline
\end{tabular}

Values are presented as mean \pm standard deviation, mean (range), or number (\%). BMI: body mass index; ICU: intensive care unit; RRT: renal replacement therapy.

aPropensity score matched values; 'Days from operation to discharge; ${ }^{\mathrm{P}} \mathrm{P}<0.05$.

derweight group and $40.5 \%$ of patients $(n=30)$ in the normal weight group (Table 4), which was not a statistically significant difference. Furthermore, there were no differences in AKI incidence among the whole cohort or between the two groups according to renal dysfunction severity among patients with postoperative AKI. In patients with normal preoperative sCr level, postoperative AKI according to the AKIN criteria occurred in $35.1 \%(n=13)$ of patients in the underweight group and $36.5 \%(n=27)$ in the normal weight group. In comparing the two groups, there was no significant difference in AKI incidence or a significant difference in renal dysfunction severity among those patients who developed postoperative AKI.

Regarding postoperative outcomes, the underweight group had significantly longer hospital stay (from operation to discharge) compared to the normal weight group (35 days [range, 14 to 222 days] vs. 26 days [range, 15 to 110 days]; $\mathrm{P}=0.02$ ). There was no significant difference in the duration of ICU stay. The number of patients on RRT, including postoperative hemodialysis, and the number of patients who died during follow-up were very low in each group, and the differences were not significant between the two groups (Table 5).

\section{Discussion}

In this retrospective review of LT recipients, BMI clas- 
sification was neither a positive nor negative predictor of postoperative AKI occurrence. However, patients with lower BMI had significantly longer hospital stay compared with their counterparts.

The term AKI is used to describe a type of renal dysfunction that progress rapidly, within hours or days, leading to accumulation of plasma urea and creatinine. Perioperative AKI is a fairly common condition, affecting $30 \%$ to $40 \%$ of all patients with AKI during hospitalization, and is associated with increased risk of sepsis, anemia, coagulopathy, cardiovascular events, and mechanical ventilation, which in turn increases morbidity, mortality, and cost $[17,18]$. Unlike the traditional belief that most patients with AKI will fully recover to baseline renal status, recent studies have suggested a significant association between AKI and chronic kidney disease $[8,9]$. The crude mortality rates among patients who developed AKI after major surgery can be as high as $50 \%$ to $60 \%$, accounting for nearly half of the overall deaths during hospitalization [3]. AKI is also known to induce distant organ damage, including pulmonary insufficiency, which can lead to increased difficulty in weaning from mechanical ventilation, and liver, cardiac, or cerebral dysfunction, which in turn contributes to up to $50 \%$ of post-LT mortality [19].

With every major surgery, there is a risk of mechanical obstruction or reduction in effective blood volume. Hypovolemia, low systemic vascular resistance due to anesthesia or caval compression, and iatrogenic injury to the renal system are all common occurrences during surgery that can cause renal-system damage [17]. Post-LT AKI occurs much more commonly than AKI in the rest of the surgical population, affecting $12 \%$ to $94 \%$ of patients [20]. The reported incidence is highly variable, but it encompasses the incidence observed in this study (30.54\%). Different definitions, case mixing, and AKI severity and location contribute significantly to the variability of incidence in previous studies, complicating interpretation and comparison of results [3,21-23]. The AKI incidence estimated for post-LT patients according to different definitions is $\mathrm{sCr}>0.5 \mathrm{mg} / \mathrm{dl}$ is $78 \%$; $\mathrm{sCr}>1.0 \mathrm{mg} / \mathrm{dL}$ is
$46 \%$; or $\mathrm{sCr}>50 \%$ from baseline to $>2 \mathrm{mg} / \mathrm{dl}$ is $14 \%$ [18]. Another study compared AKI incidence in LT patients according to the classification system used: RIFLE (Risk, Injury, Failure, Loss, and End-Stage Renal Failure), 8.0\%; AKIN, 14.31\%; and KDIGO (Kidney Disease: Improving Global Outcomes), 14.54\% [20].

Numerous factors account for the development of postLT AKI, including female sex, high Child-Pugh score, pre-existing diabetes mellitus, and a greater number of units of transfusion of blood products [12]. BMI difference has also been considered as an independent risk factor for postoperative AKI, especially in relation to comorbidities, such as metabolic syndrome, hypertension, diabetes mellitus, and coronary artery disease. However, recent studies have relied on a phenomenon known as "reverse epidemiology," in which reduced morbidity and mortality rates are observed with differences in BMI. Accordingly, a CKD cohort study by Ricardo et al. [24] found that BMI $<20 \mathrm{~kg} / \mathrm{m}^{2}$ was associated with higher risk of all-cause mortality. After the concept was first introduced in patients undergoing hemodialysis, this idea has been extensively studied and verified in other subgroups including geriatric populations in nursing homes, hospitalized patients, and patients with malignancy [25-28]. The causal pathway between BMI differences and improved clinical outcomes remains uncertain. A large animal model of post-cardiopulmonary bypass AKI in swine suggested that renal inflammation, endothelial dysfunction, and refractory cellular hypoxia are central features of AKI [29-32]. The association between BMI difference and AKI was thought to be due to attenuation of the inflammatory response [29-34]. Another study implied that renal protection was attributable to exacerbated renal inflammation, which could be due to a high-fat diet [35]. A recent study by Ouyang et al. [13] demonstrated that lower BMI is an independent risk factor for renal function deterioration due to under-nourished status and decreased complement component 3 level. Also, it was assumed that additional protein wasting might be worse tolerated in the underweight group due to low protein reserves [13]. This idea was the motivating hypothesis for this study and, thus, 
is why we classified and analyzed patients according to BMI. However, lower BMI did not correlate with AKI occurrence in post-LT patients, although it significantly increased hospital stay. Although the incidence of pulmonary complications in the two groups was comparable (4/37 vs. 5/74), the duration was longer in the underweight group, albeit not significantly so. This tendency could have influenced the longer hospital stay in patients with lower BMI.

This study has some limitations. Our results should be interpreted with caution given the small sample size and uneven BMI distribution of the sample population. Despite our best efforts to avoid any biases, this study's retrospective nature could have introduced biases that could have limited our ability to identify and analyze various confounding factors. Additionally, had we been able to include obese patients (BMI $\geq 30 \mathrm{~kg} / \mathrm{m}^{2}$ ), our results could have been different. Unfortunately, this was not possible due to loss of medical records in the small number of obese patients present in the initial cohort.

In conclusion, our findings did not show an association between BMI and post-LT AKI. However, LT recipients with lower BMI exhibited significantly longer hospital stay compared with their counterparts. A larger sample size, especially an adequate cohort of obese patients, might offer new insights for future research. Future studies should include additional endpoints such as long-term renal function as measured by $\mathrm{sCr}$, glomerular filtration rate, as well as graft and patient survival. Long-term follow-up (e.g., 5 years or longer) is necessary because AKI can take a long time to affect graft and patient survival in LT recipients.

\section{ORCID}

Ju Yeon Park http://orcid.org/0000-0002-4642-3717

Yoon Ji Choi http://orcid.org/0000-0003-3031-357X

\section{References}

1. Paramesh AS, Roayaie S, Doan Y, Schwartz ME, Emre S, Fishbein T, et al. Post-liver transplant acute renal failure: factors predicting development of endstage renal disease. Clin Transplant 2004;18:94-9.

2. Bilbao I, Charco R, Balsells J, Lazaro JL, Hidalgo E, Llopart L, et al. Risk factors for acute renal failure requiring dialysis after liver transplantation. Clin Transplant 1998;12:123-9.

3. Thakar CV. Perioperative acute kidney injury. Adv Chronic Kidney Dis 2013;20:67-75.

4. Gonwa TA, Morris CA, Goldstein RM, Husberg BS, Klintmalm GB. Long-term survival and renal function following liver transplantation in patients with and without hepatorenal syndrome: experience in 300 patients. Transplantation 1991;51:428-30.

5. Johnson JP, Johnston JR, Flick R, Singh A, Angus D, Greenberg A. Acute renal failure in recipients of organ transplantation and nontransplantation patients: comparison of characteristics and mortality. Ren Fail 1997;19:461-73.

6. Ring-Larsen H, Palazzo U. Renal failure in fulminant hepatic failure and terminal cirrhosis: a comparison between incidence, types, and prognosis. Gut 1981;22:585-91.

7. Lima EQ, Zanetta DM, Castro I, Massarollo PC, Mies S, Machado MM, et al. Risk factors for development of acute renal failure after liver transplantation. Ren Fail 2003;25:553-60.

8. Chawla LS, Kimmel PL. Acute kidney injury and chronic kidney disease: an integrated clinical syndrome. Kidney Int 2012;82:516-24.

9. Kline J, Rachoin JS. Acute kidney injury and chronic kidney disease: it's a two-way street. Ren Fail 2013;35:452-5.

10. Coca SG, Singanamala S, Parikh CR. Chronic kidney disease after acute kidney injury: a systematic review and meta-analysis. Kidney Int 2012;81:442-8.

11. Uchino S, Kellum JA, Bellomo R, Doig GS, Morimatsu H, Morgera S, et al. Acute renal failure in crit- 
ically ill patients: a multinational, multicenter study. JAMA 2005;294:813-8.

12. Hilmi IA, Damian D, Al-Khafaji A, Planinsic R, Boucek C, Sakai T, et al. Acute kidney injury following orthotopic liver transplantation: incidence, risk factors, and effects on patient and graft outcomes. $\mathrm{Br}$ J Anaesth 2015;114:919-26.

13. Ouyang Y, Xie J, Yang M, Zhang X, Ren H, Wang $\mathrm{W}$, et al. Underweight is an independent risk factor for renal function deterioration in patients with $\operatorname{IgA}$ nephropathy. PLoS One 2016;11:e0162044.

14. Yap CH, Zimmet A, Mohajeri M, Yii M. Effect of obesity on early morbidity and mortality following cardiac surgery. Heart Lung Circ 2007;16:31-6.

15. Wigfield CH, Lindsey JD, Muñoz A, Chopra PS, Edwards NM, Love RB. Is extreme obesity a risk factor for cardiac surgery? An analysis of patients with a BMI $>$ or $=40$. Eur J Cardiothorac Surg 2006;29:434-40.

16. Mehta RL, Kellum JA, Shah SV, Molitoris BA, Ronco C, Warnock DG, et al. Acute Kidney Injury Network: report of an initiative to improve outcomes in acute kidney injury. Crit Care 2007;11:R31.

17. Goren O, Matot I. Perioperative acute kidney injury. Br J Anaesth 2015;115 Suppl 2:ii3-14.

18. Bihorac A, Yavas S, Subbiah S, Hobson CE, Schold JD, Gabrielli A, et al. Long-term risk of mortality and acute kidney injury during hospitalization after major surgery. Ann Surg 2009;249:851-8.

19. Yap SC, Lee HT. Acute kidney injury and extrarenal organ dysfunction: new concepts and experimental evidence. Anesthesiology 2012;116:1139-48.

20. Erdost HA, Ozkardesler S, Akan M, Iyilikci L, Unek T, Ocmen E, et al. Comparison of the RIFLE, AKIN, and KDIGO diagnostic classifications for acute renal injury in patients undergoing liver transplantation. Transplant Proc 2016;48:2112-8.

21. Barri YM, Sanchez EQ, Jennings LW, Melton LB, Hays S, Levy MF, et al. Acute kidney injury following liver transplantation: definition and outcome. Liver Transpl 2009; 15:475-83.
22. Abelha FJ, Botelho M, Fernandes V, Barros H. Determinants of postoperative acute kidney injury. Crit Care 2009;13:R79.

23. Mehta RL, Chertow GM. Acute renal failure definitions and classification: time for change? J Am Soc Nephrol 2003;14:2178-87.

24. Ricardo AC, Anderson CA, Yang W, Zhang X, Fischer MJ, Dember LM, et al. Healthy lifestyle and risk of kidney disease progression, atherosclerotic events, and death in CKD: findings from the Chronic Renal Insufficiency Cohort (CRIC) study. Am J Kidney Dis 2015;65:412-24.

25. Kalantar-Zadeh K, Block G, Humphreys MH, Kopple JD. Reverse epidemiology of cardiovascular risk factors in maintenance dialysis patients. Kidney Int 2003;63:793-808.

26. Chang AK, Barrett-Connor E, Edelstein S. Low plasma cholesterol predicts an increased risk of lung cancer in elderly women. Prev Med 1995;24:557-62.

27. Landi F, Onder G, Gambassi G, Pedone C, Carbonin P, Bernabei R. Body mass index and mortality among hospitalized patients. Arch Intern Med 2000;160:2641-4.

28. Stevens J, Cai J, Pamuk ER, Williamson DF, Thun MJ, Wood JL. The effect of age on the association between body-mass index and mortality. N Engl J Med 1998;338:1-7.

29. Ascione R, Lloyd CT, Underwood MJ, Gomes WJ, Angelini GD. On-pump versus off-pump coronary revascularization: evaluation of renal function. Ann Thorac Surg 1999;68:493-8.

30. Murphy GJ, Lin H, Coward RJ, Toth T, Holmes R, Hall D, et al. An initial evaluation of post-cardiopulmonary bypass acute kidney injury in swine. Eur $\mathrm{J}$ Cardiothorac Surg 2009;36:849-55.

31. Patel NN, Lin H, Toth T, Welsh GI, Jones C, Ray P, et al. Reversal of anemia with allogenic RBC transfusion prevents post-cardiopulmonary bypass acute kidney injury in swine. Am J Physiol Renal Physiol 2011;301:F605-14.

32. Patel NN, Toth T, Jones C, Lin H, Ray P, George SJ, 
et al. Prevention of post-cardiopulmonary bypass acute kidney injury by endothelin A receptor blockade. Crit Care Med 2011;39:793-802.

33. Barbarroja N, López-Pedrera R, Mayas MD, GarcíaFuentes E, Garrido-Sánchez L, Macías-González M, et al. The obese healthy paradox: is inflammation the answer? Biochem J 2010;430:141-9.

34. Valentijn TM, Galal W, Tjeertes EK, Hoeks SE,
Verhagen HJ, Stolker RJ. The obesity paradox in the surgical population. Surgeon 2013;11:169-76.

35. Sleeman P, Patel NN, Lin H, Walkden GJ, Ray P, Welsh GI, et al. High fat feeding promotes obesity and renal inflammation and protects against post cardiopulmonary bypass acute kidney injury in swine. Crit Care 2013;17:R262. 